\title{
The Effects on Mood of Adjunctive Single-Family and Multi-Family Group Therapy in the Treatment of Hospitalized Patients with Major Depression
}

\author{
A 15-Month Follow-Up Study
}

\author{
Gilbert M.D Lemmens $^{a} \quad$ Ivan Eisler $^{c} \quad$ Ann Buysse $^{b}$ Els Heene ${ }^{b}$ \\ Koen Demyttenaere ${ }^{a}$ \\ a University Psychiatric Centre K.U.Leuven, Campus Leuven, Leuven, and ${ }^{b}$ Faculty of Psychology and Educational \\ Sciences, University of Ghent, Ghent, Belgium; 'Section of Family Therapy, Institute of Psychiatry, Kings College, \\ University of London, London, UK
}

\section{Key Words}

Major depression - Multi-family group therapy •

Single-family therapy

\begin{abstract}
Background: Family-based interventions have been shown to be effective in the treatment of depression, but they have seldom been studied in hospitalized depressed patients. This study assesses the value of the additional use of singlefamily or multi-family group therapy within this patient population. Methods: Eighty-three patients were randomly assigned to: (1) the treatment programme as usual ( $n=23)$, (2) treatment as usual combined with single-family therapy $(n=25)$ or (3) treatment as usual combined with multi-family group therapy $(n=35)$. Follow-up assessments were made at 3 months and 15 months. Results: Multi-family group and single-family therapy conditions showed significantly higher rates of treatment responders than the group receiving the usual treatment $(49,24$ and $9 \%$, respectively), and higher rates of patients no longer using antidepressant medication (26, 16 and $0 \%$, respectively) at 15 months. Partners taking part in the family treatments were significantly more likely to notice the improvements in the emotional health of the
\end{abstract}

patient early on compared to those in the treatment as usual condition. Conclusions: This study suggests that singlefamily and multi-family therapy may benefit hospitalized patients with major depression, and may help the partners of the patients to become aware of the patient's improvement more quickly.

Copyright $\odot 2009$ S. Karger AG, Basel

\section{Introduction}

Major depression is a highly prevalent, often recurring and persistent disorder [1-6]. One of the factors that has consistently been linked with its course and treatment response is the patient's family environment [7]. Hostility and criticism from the partner, marital distress and family functioning have been reported to predict long-term outcome and relapse rates [8-10] leading to the development of a number family-based psychosocial interventions.

The literature on empirically supported psychosocial interventions for depression includes different forms of couple therapy such as behavioural marital therapy [1114], conjoint interpersonal therapy [15], emotion-focused therapy [16], enhancing marital intimacy therapy $[17,18]$

\section{KARGER}

Fax +41613061234 E-Mail karger@karger.ch www.karger.com
(C) 2009 S. Karger AG, Basel

0033-3190/09/0782-0098\$26.00/0

Accessible online at:

www.karger.com/pps
Gilbert M.D. Lemmens, MD, PhD

Department of Psychiatry, Ghent University Hospital

De Pintelaan 185

BE-9000 Ghent (Belgium)

Tel. +329332 4395, Fax +329332 4989, E-Mail gilbert.lemmens@ugent.be 
and systemic couple therapy [19]. Although these have been mainly fairly small studies, they indicate that couple therapy has similar efficacy to cognitive therapy or antidepressant medication, particularly for distressed couples $[20,21]$. This has recently been reflected in the UK national clinical guidelines from the National Institute for Health and Clinical Excellence (NICE 2007) which recommend couple-focused interventions as one of the evidence-based treatments for depression.

The above studies have been conducted on a relatively select group of depressed patients. Most participants were female outpatients with moderately severe depressive complaints, were taking no antidepressant medication, did not have a diagnosis of psychiatric comorbidity and often had marital problems. Most of the published studies did not include a control condition, nor did they investigate the efficacy of combining psychosocial and pharmacological treatment.

Only 2 randomized controlled studies have involved patients whose depression was severe enough to require hospitalization. The results have been mixed, with 1 study [22] showing a possible negative effect at the 18-month follow-up of an inpatient psycho-educational family intervention and 1 study [23] showing higher rates of improvement and greater proportions of patients whose depression remitted after family therapy in the post-hospital period. There are virtually no empirical data on the use of other family intervention formats such as multi-family therapy groups, which are frequently offered to inpatients with major depression and their families [24-27].

The aims of the present study were (1) to investigate the efficacy of adding a family intervention to inpatient treatment of depressed individuals and (2) to compare the relative value of single-family and multi-family group therapy. Our primary hypothesis was that patients receiving family therapy would have better outcomes than those receiving only inpatient treatment and standard psychiatric follow-up. The secondary hypothesis was that the patients receiving multi-family therapy would have a better outcome than patients receiving the single-family intervention.

\section{Method}

\section{Sample Selection}

Participants were consecutive referrals to the Anxiety and Depression Unit of the University Hospital Leuven who met the inclusion criteria for the study: (1) a DSM-IV diagnosis of major depressive disorder [28], (2) aged 18-65 years, (3) cohabitating with a partner for at least 1 year and (4) informed consent pro- vided by the patient and their partner. Patients were excluded from the study if they met DSM-IV criteria for bipolar disorder [28]. Participants received a detailed explanation of the study and provided written informed consent.

\section{Participants}

Eighty-three patients and their partners participated in this study. Their sociodemographic data are shown in table 1 . No differences were found between the treatment groups except that those in multi-family therapy were more likely to have been given a diagnosis of personality disorders $\left(\chi^{2}=13.7\right.$, d.f. $\left.=4, \mathrm{p}<0.01\right)$. The patients were randomized in blocks of $4-7$, using a randomnumber table and sealed envelopes, to 1 of 3 conditions: (a) the treatment programme of the unit, i.e. treatment as usual (TAU), (b) TAU combined with single-family therapy (SFT) or (c) TAU combined with multi-family group therapy (MFT).

\section{Description of the Treatment Conditions}

The treatment programme of the Anxiety and Depression Unit, which lasts about 2-3 months, is available on an inpatient or day clinic basis. It has 2 phases: a 'problem-analysis' phase (first month) and the 'working through' phase. During each phase, specific therapeutic interventions are offered to the patients, mostly in a group format and some individually. The therapeutic techniques and interventions within the programme draw on different conceptual therapeutic frameworks such as non-verbal therapy (e.g. art therapy and relaxation), cognitive behavioural therapy (e.g. psycho-education, social skills training, functional analysis), systemic therapy (e.g. genogram group, communication training), pharmacological treatment (all except 1 patient were taking antidepressants) and activation (e.g. sport activities and ergotherapy). The relatives of newly admitted patients are invited for a family meeting to inform them about the unit and to gain information about the patient's pre-admission functioning. After discharge, patients are referred to a psychiatrist close to where they are living for further care.

In the SFT condition, patients received TAU plus 7 single-family therapy sessions. Conceptually, the model of family therapy used was based on systemic couple therapy for depression [29], incorporating social constructionist and narrative concepts, and the family systems-illness model [30]. In the systemic model, depressive symptoms of the patient are conceptualized in interactional terms, which means that close relationships are seen as both influencing and being influenced by the patient and the depressive symptoms. Initially the treatment focuses on exploring the depression within its relational context, before looking at other and wider patterns of interactions and 'quality of life' questions, and ending treatment with the discussion of possible treatment gains and relapse prevention. The aim is not primarily on altering relational distress, but to help the couples to cope better with the way depression impacts their lives. Some modifications were made for the treatment protocol compared to the original systemic couple therapy manual described by Jones and Asen [29]. First, the number of sessions was reduced to 6 biweekly sessions with the patient and their partner, and a follow-up session after 3 months. Second, the patient's children were invited to 2 of the sessions (sessions 2 and 5) with their parents in order to directly pay attention to their needs. The 'children sessions' were focused mainly on issues related to them and they were regarded as the main protagonists in these meetings. 
Table 1. Baseline characteristics of the depressed patients in the 3 treatment conditions

\begin{tabular}{|c|c|c|c|c|}
\hline & MFT $(\mathrm{n}=35)$ & TAU $(n=23)$ & SFT $(n=25)$ & $\mathrm{p}$ value \\
\hline Mean age, years & $43.9 \pm 8.3$ & $43.2 \pm 8.4$ & $40.2 \pm 9.1$ & ns \\
\hline Gender of patient, \% female & 80.0 & 69.6 & 64.0 & ns \\
\hline Duration of relationship, years & $18.7 \pm 10.0$ & $18.1 \pm 10.9$ & $14.8 \pm 9.6$ & ns \\
\hline Marital status, \% married & 82.9 & 91.3 & 88.0 & ns \\
\hline Number of children, $\%$ & & & & ns \\
\hline 0 & 28.6 & 30.4 & 24.0 & \\
\hline $1-2$ & 42.8 & 52.2 & 56.0 & \\
\hline$>2$ & 28.6 & 17.4 & 20.0 & \\
\hline Baseline dyadic adjustment scale & $98.5 \pm 23.9$ & $98.1 \pm 23.5$ & $104.9 \pm 20.5$ & ns \\
\hline Total number of depressive episodes & $2.7 \pm 1.4$ & $2.7 \pm 2.1$ & $2.3 \pm 1.4$ & ns \\
\hline Recurrent depression, $\%$ & 74.3 & 65.2 & 80.0 & ns \\
\hline Baseline Hamilton Depression Rating Scale & $17.9 \pm 6.3$ & $17.9 \pm 5.8$ & $18.0 \pm 5.7$ & ns \\
\hline Baseline Beck Depression Inventory & $26.6 \pm 9.9$ & $27.3 \pm 10.5$ & $26.2 \pm 13.5$ & ns \\
\hline Comorbid axis $1, \%$ & & & & ns \\
\hline No & 5.7 & 17.4 & 12.0 & \\
\hline Anxiety disorder & 80.0 & 65.2 & 80.0 & \\
\hline Substance abuse & 5.7 & 0.0 & 0.0 & \\
\hline Anxiety disorder and substance abuse & 8.6 & 17.4 & 8.0 & \\
\hline Personality disorder, $\%$ & & & & $0.008^{\mathrm{a}}$ \\
\hline No & 20.0 & 34.8 & 36.0 & \\
\hline Yes & 57.1 & 30.4 & 12.0 & \\
\hline Diagnosis deferred on Axis II & 22.9 & 34.8 & 52.0 & \\
\hline Duration of hospitalization, weeks & $11.3 \pm 4.5$ & $12.6 \pm 3.2$ & $12.4 \pm 3.3$ & ns \\
\hline
\end{tabular}

${ }^{\mathrm{a}} \chi^{2}=13.7$, d.f. $=4, \mathrm{p}<0.01$

The sessions followed a predetermined treatment protocol, with each session having a specific primary focus: the impact of the depression on the family (especially on the couple in session 1 and on the children in session 2); couple issues (session 3); restoring family functioning (in the couple in session 4 and the children and the family as a whole in session 5); relapse prevention (session 6); stabilizing treatment gains (session 7). Each session lasted for $60 \mathrm{~min}$. Major goals of the sessions were: to help the patients and the families to find better ways of coping with the different stages of the depression and the recovery, to accommodate their mutual efforts, to reduce the impact of the depression on the family unit, and to promote a better working alliance between the patient, the family and the therapeutic team.

In MFT, patients received TAU plus 7 sessions of multi-family group therapy. Conceptually the treatment is similar to the single-family therapy format described above, and had a comparable structure of the content and the organization of the sessions: 6 biweekly group sessions and a follow-up session after 3 months. Each group consisted of 4-7 patients and their partners (with the patients' children being invited to take part in group sessions 2 and 5). The multi-family group format affords many opportunities of helping families to learn from each others' strengths, to reduce the sense of isolation and stigma and to use the group as a resource for problem solving [24,31-34; for a detailed description of the treatment, see Lemmens et al., 35].

The sessions were conducted by a male/female co-therapy team. Sessions lasted about $90 \mathrm{~min}$ with a tea break after $60 \mathrm{~min}$.
The group leaders mainly acted as facilitators of the conversation process, encouraging the patients and their family members to share their perspectives on depression and family interactions and ensuring that all participants were able to express their experiences and perspectives.

The first sessions of both SFT and MFT took place on average $5.9 \pm 2.7$ weeks after the start of the admission (i.e. approximately halfway through the admission). No differences in time to first session $(F=0.210$, d.f. $=1, p=0.65)$ were found between the 2 family treatments.

Assessment

All patients were, as part of their admission, routinely assessed by the junior trainee psychiatrist from the unit, using the Mini International Neuropsychiatric Interview, Dutch version 5.0.0. (sections A to O) [36], and the Hamilton Rating Scale for Depression. As part of the current study, the patients further completed the Beck Depression Inventory (BDI) [37], and both they and their partners filled in the Dyadic Adjustment Scale (DAS) [38] and a rating of the subjective emotional health $(\mathrm{SEH})$ of their partner ('How would you describe the current emotional and psychological condition of your partner') rated on a 4-point Likert scale $(1=$ poor, $2=$ not very good, $3=$ quite good, $4=$ very good $)$. The $\mathrm{BDI}$ and the SEH were re-administered in month 3 (after session 6) and month 15. 


\section{Treatment Response}

Response to treatment was measured by changes in the BDI scores. In addition to the continuous measures of symptom change, we also defined 2 treatment response categories as follows: (1) 'remission' - defined as a BDI score $<9$, and (2) 'treatment response' - defined as $\geq 50 \%$ improvement on the BDI. Re-hospitalization rates were assessed at 15 months using a self-report and an additional telephone interview if necessary.

\section{Statistical Analyses}

Statistical analyses were performed after the completion of all treatments and follow-up assessment. Each outcome variable provided data at 3 time points: baseline, 3 months and 15 months follow-up. Statistical analysis of the outcome was conducted on an intention-to-treat basis, and any data available from dropouts were included. For continuous data, a maximum likelihood approach (direct likelihood) was used to deal with missing data, which produces valid parameter estimates and standard errors as long as the dropouts are not informative (missing at random). For continuous data, this method is an appropriate alternative to the commonly-used techniques, such as analyzing only treatment completers or replacing missing values with a baseline value or with the last available measurement [39], which always yield biased estimates. For categorical data, a reasonable assumption is that dropouts have not made progress, and therefore carrying forward the last available measurement can be justified. Any bias introduced in this way is likely to be conservative in this case. In order to check for possible bias, the analyses were repeated using subjects with complete datasets [40].

The baseline characteristics of the patients in the 3 treatment conditions were compared using 1-way ANOVA and $\chi^{2}$ analyses. Treatment effects were compared using a series of 3 (MFT vs. TAU vs. SFT) $\times 3$ (baseline vs. 3 months vs. 15 months) linear mixed models for repeated measurements (direct likelihood) on the scores of the BDI, and using a series of 3 (MFT vs. TAU vs. SFT) $\times 3$ (baseline vs. 3 months vs. 15 months) $\times 2$ (patient vs. partner) multivariate ANOVA on the scores of the SEH. Differences in treatment responders, treatment remission, re-hospitalization, suicide rates, and use of antidepressant medication between the treatment conditions were compared using $\chi^{2}$ analyses, Fisher's exact test and 1-way ANOVA. In order to control for the imbalance resulting from the random allocation to the 3 treatment groups, a diagnosis of personality disorder was entered as a covariate in the analysis.

\section{Results}

\section{Patients' Progress through the Trial}

All 83 patients and their partners were randomized, following assessment, to the 3 treatment conditions. Of the 35 patients, who were randomized to MFT, 6 (17.1\%) dropped out from treatment: 1 patient did not start therapy and another 5 patients stopped attending the group early. No follow-up data were available for 8 patients at 3 months (22.9\%; 4 dropouts and 4 completers) and 10 patients at 15 months $(28.6 \%$; 5 dropouts and 5 completers) since they did not return the questionnaires. Patients in this treatment condition participated on average in $5.4 \pm$ 1.8 sessions and their 34 partners in $5.1 \pm 2$ sessions. Thirty-six of their children (mean age: 15.5 years, range: 5-32 years, 19 boys and 17 girls) participated on average in 1.3 sessions.

In SFT, 3 patients (12\%) dropped out from treatment: 1 patient did not start therapy and another 2 patients stopped the family sessions early. The patients participated on average in $6.8 \pm 0.6$ sessions and their partners in $6.7 \pm 0.8$ sessions. Thirty-four of their children (mean age: 14.1 years, range: $6-30$ years, 16 girls and 18 boys) participated on average in 1.3 sessions. Six patients at 3 months (24\%; 3 dropouts and 3 completers) and 8 patients at 15 months (32\%; 3 dropouts and 5 completers) did not return the questionnaires.

In the TAU condition, questionnaires were not filled out by 10 patients at 3 months (43.5\%) and 12 patients at 15 months (52.2\%). Despite the higher frequency of lost data in the TAU condition, no statistically significant differences in the frequency of lost data were found between the 3 treatment conditions at 3 months $\left(\chi^{2}=3.3\right.$, d.f. $=2$, $p=0.19)$ and 15 months $\left(\chi^{2}=3.6\right.$, d.f. $\left.=2, p=0.16\right)$. The group of patients who did not complete their assessments at 3 and 15 months did not differ from those who did, with one exception in that they had a more frequent comorbid diagnosis of substance abuse at baseline (29.1 vs. $6.8 \%, \chi^{2}=9.4$, d.f. $=3, p<0.05$, and 26.71 vs. $5.7 \%, \chi^{2}=$ 9.0, d.f. $=3, \mathrm{p}<0.05$, respectively).

No differences were found in treatment dropout rates between the 2 family therapy conditions $\left(\chi^{2}=0.3\right.$, d.f. $=$ $1, \mathrm{p}=0.58)$. Dropouts from SFT and MFT were significantly older (51.0 vs. 41.6 years, $\mathrm{F}=10.6$, d.f. $=81, \mathrm{p}<$ 0.005 ), with a longer relationship (23.9 vs. 16.6 years, $\mathrm{F}=$ 4.4 , d.f. $=82, \mathrm{p}<0.05)$, were hospitalized for a shorter period (9.4 vs. 12.3 weeks, $\mathrm{F}=4.6$, d.f. $=82, \mathrm{p}<0.05)$, were more likely to be males (55.6 vs. $24.3 \%, \chi^{2}=3.9$, d.f. $=1$, $\mathrm{p}<0.05)$ and had more frequent diagnoses of comorbidity, especially substance abuse ( 44.4 vs. $9.5 \%, \chi^{2}=9.5$, d.f. $=3, \mathrm{p}<0.05)$ at baseline.

\section{Effects of Treatment}

Overall, the BDI scores decreased significantly over time in all treatment conditions $(\mathrm{F}=39.52$, d.f. $=1, \mathrm{p}<$ 0.0001 ; table 2), but the observed differences between treatments, which seemed to favour MFT and SFT in comparison with TAU, were not statistically significant $(\mathrm{F}=1.29$, d.f. $=2, \mathrm{p}=0.28)$. Between the 3-month and 15month follow-up there were continuing improvements in mood in patients in the two family treatments, but BDI scores remained unchanged for those in TAU. 
Table 2. Effects of treatment on depressive symptoms, re-hospitalization rates, SEH and medication use

\begin{tabular}{|c|c|c|c|c|}
\hline & $\operatorname{MFT}(\mathrm{n}=35)$ & TAU $(n=23)$ & SFT $(n=25)$ & $\mathrm{p}$ value \\
\hline \multicolumn{5}{|l|}{ BDI } \\
\hline Baseline & $26.6 \pm 9.9$ & $27.3 \pm 10.7$ & $26.2 \pm 13.5$ & ns \\
\hline 3 months & $18.7 \pm 9.1$ & $21.9 \pm 10.8$ & $19.3 \pm 10.7$ & ns \\
\hline 15 months & $15.8 \pm 13.7$ & $22.2 \pm 15.6$ & $12.5 \pm 9.8$ & ns \\
\hline \multicolumn{5}{|l|}{ Treatment responders } \\
\hline 3 months & $8(22.9)$ & $3(13.0)$ & $5(20.0)$ & ns \\
\hline 15 months & $17(48.6)$ & $2(8.7)$ & $6(24.0)$ & $0.004^{\mathrm{a}}$ \\
\hline \multicolumn{5}{|l|}{ Treatment remission } \\
\hline 3 months & $7(20.0)$ & $3(13.0)$ & $4(16.0)$ & ns \\
\hline 15 months & $13(37.1)$ & $4(17.4)$ & $7(28.0)$ & ns \\
\hline Re-hospitalization rates at 15 months & $8(23.5)$ & $7(33.3)$ & $3(12.5)$ & ns \\
\hline Suicide rates at 15 months & $0(0)$ & $1(4.3)$ & $1(4.0)$ & ns \\
\hline \multicolumn{5}{|l|}{ Not using antidepressant medication } \\
\hline Baseline & $1(2.9)$ & $0(0)$ & $0(0)$ & ns \\
\hline 3 months & $3(8.6)$ & $2(8.7)$ & $1(4.0)$ & ns \\
\hline 15 months & $9(25.7)$ & $0(0)$ & $4(16.0)$ & $0.031^{\mathrm{b}}$ \\
\hline \multicolumn{5}{|l|}{ SEH of partner by the patient } \\
\hline Baseline & $2.8 \pm 0.5$ & $2.9 \pm 0.6$ & $2.9 \pm 0.7$ & ns \\
\hline 3 months & $3.2 \pm 0.5$ & $3.0 \pm 0.8$ & $3.3 \pm 0.6$ & ns \\
\hline 15 months & $3.3 \pm 0.5$ & $3.0 \pm 0.9$ & $3.2 \pm 0.6$ & ns \\
\hline \multicolumn{5}{|l|}{ SEH of patient by the partner } \\
\hline Baseline & $1.7 \pm 0.8$ & $1.6 \pm 0.7$ & $1.7 \pm 0.9$ & ns \\
\hline 3 months & $2.6 \pm 0.6$ & $1.9 \pm 0.8$ & $2.3 \pm 0.8$ & $0.029^{c}$ \\
\hline 15 months & $2.7 \pm 0.6$ & $3.1 \pm 0.3$ & $3.0 \pm 0.4$ & ns \\
\hline Psychiatric consultations after discharge & $16.5 \pm 21.2$ & $11.6 \pm 10.3$ & $11.1 \pm 8.6$ & ns \\
\hline
\end{tabular}

Values are given as means \pm SD. Figures in parentheses are percentages.

${ }^{\mathrm{a}} \chi^{2}=11.12$, d.f. $=2, \mathrm{p}<0.005 .{ }^{\mathrm{b}} \chi^{2}=6.95$, d.f. $=2, \mathrm{p}<0.05 .{ }^{\mathrm{c}} \mathrm{F}=3.8$, d.f. $=2, \mathrm{p}<0.05$.

Table 2 shows that at 15 months the proportion of treatment responders (i.e. with an improvement in BDI scores of at least 50\%) was significantly higher in the family treatments than in TAU $\left(\chi^{2}=11.12\right.$, d.f. $\left.=2, \mathrm{p}<0.005\right)$. A paired comparison showed a significant difference between MFT and TAU ( $p=0.001$, Fisher's test) and between MFT and SFT ( $p=0.047$, Fisher's test), but not between SFT and TAU. There was a similar pattern favouring MFT and SFT for patients in remission (a BDI score $<9)$, but this difference did not reach statistical significance. There were also no significant differences in rehospitalization, suicide rates and in use of psychiatric outpatient services in the period between discharge and 15 months.

All but one patient in the study were taking antidepressants at baseline, and this was still true of approximately $85 \%$ at follow-up. However, this varied significantly between treatments. At the 15-month follow-up, none of those in TAU had stopped using antidepressants, whereas $16 \%$ of those in SFT and 26\% in MFT had stopped $\left(\chi^{2}=6.95\right.$, d.f. $\left.=2, p<0.05\right)$. In the 2 -way comparisons at 15 months, the MFT versus TAU comparison was statistically significant ( $p=0.007$, Fisher's test), while the TAU versus SFT was just outside the $5 \%$ level of significance $(\mathrm{p}=0.06$, Fisher's test). People may of course discontinue the use of antidepressants for a variety of reasons other than improvements in mood. We therefore compared the BDI scores of those who were not taking medication with those who were. The mean scores $(6.0 \pm 8.7$ and $18.8 \pm$ 12.6 , respectively) were significantly different $(t=3.35$, d.f. $=48, \mathrm{p}<0.005)$. In fact, only 2 of the 13 patients who were not using antidepressants had BDI scores $>9$.

\section{SEH as Perceived by the Partner}

An important aspect of family interventions is exploring the different perceptions that family members have of each other as these influence behaviours, beliefs and selfperceptions. The significance of this is revealed in the changes of partners' perceptions of each others' emotional health (table 2). The SEH as perceived by the partner 
differed significantly over time, the treatment condition and the patients/partners with a statistically significant time $\times$ treatment $(\mathrm{F}=3.0$, d.f. $=4, \mathrm{p}<0.05)$ and partner/ patient $\times$ time $\times$ treatment effect $(\mathrm{F}=4.8$, d.f. $=4, \mathrm{p}<$ 0.005). The patients did not report an improvement in the SEH of their partners in TAU, in contrast with the patients in the 2 family treatments. Moreover, the patients in MFT and SFT were seen as improved by their partners on the SEH at both 3 and 15 months, whereas the patients in TAU were only reported to be improved by their partners at 15 months. At 3 months, the SEH of the patient as perceived by the partner differed significantly between treatments $(\mathrm{F}=3.8$, d.f. $=2, \mathrm{p}<0.05)$, but by the time of the follow-up the difference had disappeared. More detailed contrast analysis using a 2-way comparison (MFT vs. TAU, MFT vs. SFT, SFT vs. TAU) for the patients and the partners separately revealed a significant time $\times$ treatment interaction for the patients $(\mathrm{F}=3.9$, d.f. $=2$, $\mathrm{p}<0.05)$ as well as for the partners $(\mathrm{F}=6.48$, d.f. $=2$, $\mathrm{p}<0.01)$ only when comparing MFT with TAU.

\section{Observed Cases Analysis}

In order to check for potential bias arising out of using the last available measurements to replace missing data these analyses were repeated using a reduced data set omitting participants with missing data [40]. The results remained essentially the same with all statistically significant findings remaining significant. The one exception was the difference in the proportion of treatment responders found between MFT and SFT, which in the more restricted dataset was not statistically significant $(\mathrm{p}=0.08$, Fisher's test $)$.

\section{Discussion}

This study investigated the effects of adding single- or multi-family therapy to the treatment of hospitalized patients with major depression. Before discussing our findings, potential limitations need to be addressed. The first is that almost twice as many participants in TAU did not return questionnaires compared with the other treatments. Withdrawal from research (typically $25 \%$ and up to $50 \%$ ) is a frequent problem in treatment trials for depression [41, 42], but it is of particular concern if it is not balanced between treatments. If we assume that those who failed to return questionnaires include a larger proportion of patients not doing well, the results would be skewed either in favour of family therapy (if missing data are being replaced) or in favour of TAU (if cases with missing data are omitted from the analysis). The fact that the 2 ways of dealing with missing data that we used led to essentially the same findings goes some way towards mitigating these concerns. The less subjective finding that there were differences between the treatments in the use of antidepressants at follow-up also increases the confidence in the results.

The relatively small size of the sample was a further limitation, increasing the risk of false-negative conclusions and requiring a degree of caution when interpreting the results, particularly the relative lack of differentiation between MFT and SFT. The study would also have been strengthened if available resources had allowed the use of observer ratings at follow-up. However, the BDI is a robust self-report measure for the assessment of depression severity and change $[43,44]$.

Bearing the above caveats in mind, the results of this study provide additional evidence for the role of family therapy in the treatment of depression. While there were significant improvements in all patients over time, the decrease of depressive symptoms was more pronounced for patients receiving a family intervention compared to those in TAU. It was notable that the depression in TAU patients decreased mainly in the first 3 months, whereas the patients in both family treatments continued to improve throughout follow-up - a finding similar to that reported by Leff et al. [19]. At 15 months, less than $10 \%$ of those in TAU were classified as 'treatment responders', whereas a quarter of those in SFT and nearly half of those in MFT reached this criterion; a finding similar to that of Miller et al. [23], showing the value of adjunctive family therapy following hospital treatment. It is important to note that in spite of the extensive treatment, the response and remissions rates were quite modest at follow-up. This may partly reflect the difficulties in achieving recovery for this particular group of recurrently depressed patients with high psychiatric comorbidity, and the importance of developing alternate or sequential forms of treatments $[6$, $45,46]$. The limited treatment response, however, could also be due to the relatively brief family intervention ( 7 sessions), and it is possible that a longer treatment might have led to greater improvements.

The patients in the 2 family intervention groups, but particularly those in the multi-family group, were using less antidepressant medication at 15 months than patients receiving TAU. Our data suggest that this was at least in part due to the patients being less depressed, but caution is needed in interpreting this finding given the evidence that lower doses of antidepressants can be associated with higher relapse rates [47]. 
The family treatments had an additional advantage compared to TAU in that they helped partners to recognize the improvements in mood sooner (at 3 months for partners in SFT or MFT compared to 15 months in TAU). This could have been due to an increase in their awareness of the patient's condition allowing them to notice more readily improvements in mood, or alternately the focus of the family discussions on positive aspects of the patient's functioning could have helped the partners put the depression more quickly into perspective.

Differences between the 2 family interventions were relatively small. MFT was more clearly differentiated on a number of measures (use of medication, responder rates, subjective emotional health of patients and their partners) from TAU than was the case for SFT. Although we found a significant difference in the proportion of responders between the 2 family interventions, this finding needs to be interpreted with caution given the limitations described earlier. Nevertheless, the finding is consistent with other research which has shown MFT to be at least as effective or more so in reducing symptoms and/or relapse rates than single-family interventions in the treatment of schizophrenia [48-52] or eating disorder [53], for example. Additional benefits of MFT found in other studies (e.g. improved communication, overcoming stigmatization and reduction of social isolation [34, 54-58]) were not addressed in this study and need more investi- gation in depression. Future research should also pay attention to the question of economic health costs of both types of family interventions.

Our study indicates that both SFT and particularly MFT may benefit hospitalized patients with major depression, improving treatment response and reducing the use of medication, although these results should be replicated before being implemented in routine clinical settings. The differences between treatments in the way partners' perceptions of the patients' well-being evolved points to a potentially important area for future investigation as this might be a possible mediator of treatment. We found insufficient evidence to be able to say with confidence that MFT confers greater benefit in the treatment of depression than SFT. Nevertheless, the clearer findings of changes in both patients and their partners in response to MFT point to the potential value of this treatment, and the need for further research to evaluate the effectiveness of MFT for depression and the therapeutic mechanisms that underpin it.

\section{Acknowledgements}

The authors thank Prof. Dr. Herbert Thijs (Center for Statistics, Hasselt University, Belgium) and Rob Stroobants (Department of Psychology, Catholic University Leuven, Belgium) for their assistance in the data analysis.

\section{References}

1 Judd LL: The clinical course of unipolar major depressive disorders. Arch Gen Psychiatry 1997;54:989-991.

-2 Ormel J, Van den Brink W, Koeter MWJ, Giel R, Van der Meer K, Van de Willige G, Wilmink FW: Recognition, management and outcome of psychological disorders in primary care: a naturalistic follow-up study. Psychol Med 1990;20:909-923.

-3 Solomon DA, Keller MB, Leon AC, Mueller TI, Lavori PW, Shea T, Coryell W, Warshaw M, Turvey C, Maser JD, Endicott J: Multiple recurrences of depressive disorders. Am J Psychiatry 2000;157:229-233.

-4 Fava GA, Ruini C, Sonino N: Management of recurrent depression in primary care. Psychother Psychosom 2003;72:3-9.

5 Fava GA, Ruini C, Belaise C: The concept of recovery in major depression. Psychol Med 2007:37:307-317.

-6 Fava GA, Tomba E, Grandi S: The road to recovery from depression - don't drive today with yesterday's map. Psychother Psychosom 2007;76:260-265.
7 Heru AM: Family psychiatry: from research to practice. Am J Psychiatry 2006;163:962968.

8 Hooley JM, Teasdale JD: Predictors of relapse in unipolar depressives: expressed emotion, marital distress, and perceived criticism. J Abnorm Psychol 1989;3:229-235.

-9 Keitner GI, Ryan CE, Miller IW, Norman WH: Recovery and major depression: factors associated with 12 month outcome. Am J Psychiatry 1992;149:93-99.

10 Whisman MA: The association between depression and marital dissatisfaction; in Beach SRH (ed): Marital and Family Processes in Depression: A Scientific Foundation for Clinical Practice. Washington, American Psychological Association, 2001, pp 3-24.

11 O'Leary KD, Beach SRH: Marital therapy: a viable treatment for depression and marital discord. Am J Psychiatry 1990;147:183-186.
12 Jacobson NS, Dobson K, Fruzetti AE, Schmaling KB, Salusky S: Marital therapy as a treatment for depression. J Consult Clin Psychol 1991;59:547-557.

13 Beach SRH, O'Leary KD: Treating depression in the context of marital discord: outcome and predictors of response for marital therapy versus cognitive therapy. Behav Ther 1992;23:507-529.

14 Emmanuels-Zuurveen L, Emmelkamp PM: Individual behavioural-cognitive therapy v. marital therapy for depression in maritally distressed couples. Br J Psychiatry 1996;169: 181-188.

15 Foley SH, Rounsaville BJ, Weissman MM, Sholomskas D, Chevron E: Individual versus conjoint interpersonal psychotherapy for depressed patients with marital disputes. Int J Fam Psychiatry 1989;10:29-42.

16 Dessaulles A, Johnson SM, Denton WH: Emotion-focused therapy for couples in the treatment of depression: a pilot study. Am J Fam Ther 2003;31:345-353. 
17 Waring EM: The role of marital therapy in the treatment of depressed married women. Can J Psychiatry 1994;39:568-571.

- 18 Waring EM, Chamberlaine CH, Carver CM, Stalker CA, Schaefer B: A pilot study of marital therapy as a treatment for depression. Am J Fam Ther 1995;23:3-10.

-19 Leff J, Verneals S, Brewin CR, Wolff G, Alexander B, Asen E, Dayson D, Jones E, Chisholm D, Everitt B: The London Depression Intervention Trial. Randomised controlled trial of antidepressants v. couple therapy in the treatment and maintenance of people with depression living with a partner: clinical outcome and costs. Br J Psychiatry 2000; 177:95-100.

20 Beach S: Affective disorders. J Marital Fam Ther 2003;29:247-261.

21 Gupta M, Coyne JC, Beach SJR: Couples treatment for major depression: critique of the literature and suggestions for different directions. J Fam Ther 2003;25:317-346.

-22 Clarkin JF, Glick ID, Haas GL, Spencer JH, Lewis AB, Peyser J, DeMane N, Good-Ellis $\mathrm{M}$, Harris E, Lestelle V: A randomized clinical trial of inpatient family intervention. V. Results for affective disorders. J Affect Disord 1990;18:17-28.

-23 Miller IW, Keitner GI, Ryan CE, Solomon DA, Cardemil EV, Beevers CG: Treatment matching in the posthospital care of depressed patients. Am J Psychiatry 2005;162: 2131-2138.

-24 Anderson CM, Griffin S, Rossi A, Pagonis I, Holder DP, Treiber R: A comparative study of the impact of education versus process groups for families of patients with affective disorders. Fam Process 1986;25:185-205.

25 Harter C, Kick J, Rave-Schwank M: Psychoeducational groups for patients with depression and their families. Psychiat Prax 2002; 29:160-163.

26 Keller F, Schuler B: Psychoeducational groups for families of in-patients with affective disorder: experiences with a person-oriented approach. Psychiat Prax 2002;29:130135 .

27 Keitner GI, Drury LM, Ryan CE, Miller IW, Norman WH, Solomon DA: Multifamily group treatment for major depressive disorder; in McFarlane WR (ed): Multifamily Groups in the Treatment of Severe Psychiatric Disorders. New York, Guilford Press, 2002, pp 244-267.

28 American Psychiatric Association: Diagnostic and Statistical Manual of Mental Disorders, ed 4. Washington, American Psychiatric Press, 1994

29 Jones E, Asen E: Systemic Couple Therapy and Depression. London, Karnac Books, 2002.

30 Rolland JS: Families, Illness, and Disability: An Integrative Treatment Model. New York, Basic Books, 1994.
31 Lemmens G, Heireman M, Sabbe B: Familiediscussiegroepen: Methodiek en processen. Systeemtherapie 2001;13:72-85.

32 Lemmens GM, Wauters S, Heireman M, Eisler I, Lietaer G, Sabbe B: Beneficial factors in family discussion groups of a psychiatric day clinic: perception by the therapeutic team and the families of the therapeutic process. J Fam Ther 2003;25:41-63.

33 Asen E: Multiple family therapy: an overview. J Fam Ther 2002;24:3-16.

34 Eisler I: The empirical and theoretical base of family therapy and multiple family day therapy for adolescent anorexia nervosa. J Fam Ther 2005;27:104-131.

35 Lemmens GMD, Eisler I, Migerode L, Heireman M, Demyttenaere K: Family discussion group therapy for major depression: a brief systemic multi-family group intervention for hospitalised patients and their family members. J Fam Ther 2007;29:49-68.

36 Overbeek T, Schruers K, Griez E: M.I.N.I.: Mini International Neuropsychiatric Interview, Dutch version 5.0.0 (DSM-IV). Maastricht, University of Maastricht, 1999.

37 Beck AT, Ward CH, Mendelson M, Mock J, Erbaugh J: An inventory for measuring depression. Arch Gen Psychiatry 1961;4:561571.

38 Spanier GB: Measuring dyadic adjustment: new scales for assessing the quality of marriage and similar dyads. J Marriage Fam 1976;38:15-28.

-39 Schluchter MD: Analysis of incomplete multivariate data using linear models with structured covariance matrices. Stat Med 1988;7: 317-324.

40 Gaudiano BA, Herbert JD: Methodological issues in clinical trials of antidepressant medications: perspectives from psychotherapy outcome research. Psychother Psychosom 2005;74:17-25.

41 Lazaratou H, Anagnostopoulos DC, Vlassopoulos M, Tzavara C, Zelios G: Treatment compliance and early termination of therapy: a comparative study. Psychother Psychosom 2006;75:113-121.

42 Arnow BA, Blasey C, Manber R, Constantino MJ, Markowitz JC, Klein DN, Thase ME, Kocsis JH, Rush AJ: Dropouts versus completers among chronically depressed outpatients. J Affect Disord 2007;97:197-202.

43 Demyttenaere K, De Fruyt J: Getting what you ask for: on the selectivity of depression rating scales. Psychother Psychosom 2003; 72:61-70.

44 Bech P, Hansen HV, Kessing LV: The internalising and externalising dimensions of affective symptoms in depressed (unipolar) and bipolar patients. Psychother Psychosom 2006;75:362-369.
45 Blom MBJ, Jonker K, Dusseldorp E, Spinhoven P, Hoencamp E, Haffmans, van Dyck $\mathrm{R}$ : Combination treatment for acute depression is superior only when psychotherapy is added to medication. Psychother Psychosom 2007:76:289-297.

46 Gaudiano BA, Miller IW, Herbert J: The treatment of psychotic major depression: is there a role for adjunctive psychotherapy? Psychother Psychosom 2007;76:271-277.

-47 Papakostas GI, Perlis RH, Seifert C, Fava M: Antidepressant dose reduction and the risk of relapse in major depressive disorder. Psychother Psychosom 2007;76:266-270.

$\checkmark 48$ Leff J, Berkowitz R, Shavit N, Strachan A, Glass I, Vaugh C: A trial of family therapy versus a relatives' group for schizophrenia: two year follow-up. Br J Psychiatry 1990;157: 571-577.

49 McFarlane WR, Lukens E, Link B, Dushay R, Deakins SA, Newmark M, Dunne EJ, Horen B, Toran J: Multiple-family groups and psychoeducation in the treatment of schizophrenia. Arch Gen Psychiatry 1995;52:679687.

50 Schooler NR, Keith SJ, Severe JB, Matthews SM, Bellack AS, Glick ID, Hargreaves WA, Kane JM, Ninan PT, Frances A, Jacobs M, Lieberman JA, Mance R, Simpson GM, Woerner MG: Relapse and rehospitalization during maintenance treatment of schizophrenia: the effects of dose reduction and family treatment. Arch Gen Psychiatry 1997; 54:453-463.

51 Mueser KT, Sengupta A, Schooler NR, Bellack AS, Xie H, Glick ID, Keith SJ: Family treatment and medication dosage reduction in schizophrenia: effects on patient social functioning, family attitudes and burden. J Consult Clin Psychol 2001;69:3-12.

-52 Montero I, Hernandez I, Asencio A, Bellver F, LaCruz M, Masanet MJ: Do all people with schizophrenia receive the same benefit from different family intervention programs? Psychiat Res 2005;133:187-195.

53 Geist R, Heinmaa M, Stephens D, Davis R, Katzman DK: Comparison of family therapy and family group therapy psychoeducation in adolescents with anorexia nervosa. Can J Psychiatry 2000;45:173-178.

-54 Steinglas P: Multiple family discussion groups for patients with chronic medical illness. Fam Syst Health 1998;16:55-70.

55 McFarlane WR: Multifamily Groups in the Treatment of Severe Psychiatric Disorders. New York, Guilford Press, 2002

56 Poser M: Anorexia nervosa - my story. J Fam Ther 2005;27:142-143.

57 Poser M: Anorexia nervosa - a parent's perspective. J Fam Ther 2005;27:144-146.

58 Scholz M, Rix M, Scholz K, Gantchev K, Thömke V: Multiple family therapy for anorexia nervosa: concepts, experiences and results. J Fam Ther 2005;27:132-141. 